\title{
REMINERALIZING POTENTIAL OF SALIVA ON PATIENTS HAVING DENTALEROSIONS DUE TO WINE CONSUMPTION
}

\author{
Nicoleta Tofan ${ }^{1 \mathrm{a}}$, Sorin Andrian ${ }^{1 \mathrm{~b}^{\star}}$, Irina Nica ${ }^{1 \mathrm{c},}$ Simona Stoleriu ${ }^{1 \mathrm{~d}}$, \\ Claudiu Topoliceanu ${ }^{1 \mathrm{e}}$, Petru Edward Nica ${ }^{2 f}$, Maria Bolat ${ }^{19}$, Galina Pancu ${ }^{\text {th }}$
}

1Department of Odontology, Periodontology and Fixed Prosthodontics, Faculty of Dental Medicine

"Grigore T. Popa" University of Medicine and Pharmacy of Jassy, Jassy, Romania

2Department of Physics, "Gheorghe Asachi" Technical University of Jassy, Jassy, Romania

aDDS, PhD Student

${ }^{b} D D S$, PhD, Professor

'DDS, PhD, Assistant Professor

'DDS, PhD, Lecturer

${ }^{e} \mathrm{DDS}$, PhD, Assistant Professor

'DDS, PhD, Professor,

${ }^{9} \mathrm{DDS}, \mathrm{PhD}$, Assistant Professor

"DDS, PhD, Assistant Professor

Received: April 10, 2016 Received in revised form: April 24, 2016 Accepted: May 1,2016

Cite this article:

Tofan N, Andrian S, Nica I, Stoleriu S, Topoliceanu C, Nica PE, Bolat M, Pancu G. Remineralizing potential of saliva on patients having dental erosions due to wine consumption. Stoma Edu J. 2016; 3(1-2):16-21.

Introduction: The aim of the study is to assess the action of a remineralizing product (calcium-phosphatefluoride-based varnish) on the saliva remineralization capacity on patients having dental erosions caused by frequent wine consumption.

Methodology: The study group was made up of 15 patients who are frequent wine consumers. Unstimulated saliva was collected on the same day and at the same hour for each patient. A total amount of $0.5 \mathrm{ml}$ of unstimulated saliva was placed on a glass plate, dried for 30 minutes in a thermostat at $+37^{\circ} \mathrm{C}$, and then studied using a Nikon Eclipse E 600. The images were saved and stored on a computer. The IMK index was determined using the formula: IMK= number of the network areas filled with crystals/ number of the network areas projected on the entire saliva drop. The treatment plan for each patient included a five-week application of MI Varnish (GC Corporation) once a week. After 5 weeks IMK values were recorded again.

Results: The mean value of IMK increased from 0.33 before treatment to 0.83 after treatment. The distribution of micro-crystallization categories varied from 86\% Type II before treatment to $93 \%$ Type I after treatment.

Conclusions: The fluor local treatment that uses varnishes containing casein phosphopeptide, tri-calcium phosphate, amorphous calcium phosphate and fluoride, increase the saliva remineralising potential and can be recommended both as preventive therapy and to counteract the erosive effect of acid oral environment on patients with dental erosions related to the frequent consumption of wine. Local treatment with GC Recaldent MI Varnish increased the remineralizing potential of saliva on patients with dental erosions due to wine consumption.

Keywords: erosion, wine, salivary micro-crystallization index, remineralization.

\section{Introduction}

Non-carious lesions are chemical, mechanical and corosive complex processes. Despite the existance of numerous and various studies related to the topic, the issue is still considered a challenge for modern dentistry. Many questions remain unanswered regarding the definitions, factors and mechanisms of non-carious lesions. Some researchers such as P. Fouchard ${ }^{1}$ and others ${ }^{2-4}$ tried to explain the non-carious dental loss as related especially to chemical exogenous and endogenous factors.

G.V. Black defined, in 1908, dental erosion as related to the effects of acid on dental tissues. $\mathrm{He}$ identified factors related to dental erosions as follows: defects of teeth formation, dental loss related to powder products, unknown acids, decreased saliva secretion, increased consumption of beverages, action of alkaline fluids on calcium 
salts, action of enzyme released by bacteria. Also other early studies focused on factors and processes related to dental erosions. ${ }^{5-7}$

The success of dental erosions therapy depends on the preventive and therapeutical strategy that must be focused on the risk assessment, oral hygiene practices, diet, lifestyle, medical factors. The long-term success is related to the possibilities to improve the saliva environment quality and regular application of remineralising protocols. Some studies ${ }^{8-15}$ proved the effectiveness of products based on calcium and phosphate in the erosion lesion onset.

Initially, dental erosion is associated with enamel loss of a few micrometers, a process known as demineralization. Demineralization is associated to a decrease in the calcium and phosphate ions concentration. In time, the loss can affect the entire enamel layer. Factors like the remineralisation process and acquired pellicle formation can reduce the rate of dental erosion. De- and remineralisation processes alternate on long time intervals.

Remineralization is influenced by the concentration of calcium and phosphate ions in saliva. Previous studies $^{16-19}$ showed a direct correlation between the remineralizing capacity of saliva and the aspect of saliva crystals on microscopy analysis. Patients having high remineralizing capacity of saliva presented, in $93.5 \%$ of the cases, an aspect of fern-shaped crystals, with the highest crystals concentration in the middle of saliva drop. Patients with low remineralising capacity of saliva presented no such this structure or it was difuse in $87 \%$ of the cases and saliva presented a few crystals in the visual field or some needle-shaped crystals, homogeneously distributed or grouped to the periphery of the saliva drop. ${ }^{16,17}$

Dental erosion is influenced by a lot of internal and external factors. ${ }^{20-25}$ The most important factor is considered the frequent consumption of beverages, including cola-like drinks, high acid drinks and wine. ${ }^{26,27}$

The frequent consumption of wine (alcoholism) or professional exposure to wines represent major factors in the dental erosions onset. ${ }^{28-30}$ The erosive potential of red wine, white wine, and champagne is related to the presence of lactic acid, citric acid, malic acid, and tartaric acid.

The treatment of dental erosions is based on the removal of etiological factors and the use of remineralizing products containing calcium, phosphate, fluoride, magnesium, and zinc. ${ }^{16,22}$

The aim of study was to assess the action of a remineralizing product (calcium-phosphatefluoride based varnish) on the remineralizing capacity of saliva on patients having dental erosions related to frequent wine consumption.

\section{Metodology}

The study group was made up of 15 patients who are frequent wine consumers (minimum 5 times a day), age 30-50, having dental erosions. The patients were selected from patients treated in the Dental Clinic of the Dental Medicine Faculty, "Gr. T. Popa" University of Medicine and Pharmacy, Jassy. After clinical examination the remineralizing capacity of saliva was evaluated using microcrystallization index (IMK). For IMK evaluation, unstimulated saliva was collected in a test tube before 12 a.m. From this saliva, $0.5 \mathrm{ml}$ were applied on a microscope slide; the saliva liquid was dried for 30 minutes in $37^{\circ} \mathrm{C}$ temperature. The microscopy analysis was performed using Nikon Eclipse E 600 , and images were recorded and stored in a computer. The IMK micro-crystallization index was calculated using the following formula:

\begin{tabular}{|c|c|}
\hline \multirow{2}{*}{$\mathrm{IMK}=$} & $\begin{array}{c}\text { number of points of numbering grill projected } \\
\text { on crystals }\end{array}$ \\
\cline { 2 - 2 } & $\begin{array}{c}\text { number of points of numbering grill projected } \\
\text { on saliva drop }\end{array}$ \\
\hline
\end{tabular}

The IMK values were divided in three types, namely high, moderate and low level of crystallization. The basic criteria for the crystals evaluation were the diameter, shape and number. The mean values of IMK between 0.6 and 1 were included in type I of crystallization, values between 0.4 and 0.6 were included in type $\mid \mathrm{I}$ and values between 0 and 0.4 were included in type III. The treatment plan for each patient included a weekly application of MI Varnish (GC Corporation, Tokyo, Japan) for 5 weeks. Saliva was evaluated at the baseline and after 5 weeks.

\section{Results}

The IMK values before and after treatment are presented in Tabel 1. The mean value of IMK increased from 0.33 before treatment to 0.83 after treatment after treatment.

The distribution of the micro-crystallization categories varied from 86\% Type II before treatment to 93\% Type I after treatment.

The types of micro-crystallization were represented by needle-shaped, fern-shaped, tree-shaped, flakeshaped, oval-shaped or cubic-shaped crystals, as well as their multiple points or combinations (Figs 1-6).

Before treatment $86 \%$ of the IMK values were included in type II category of micro-crystallization and $14 \%$ in type III. After treatment $93 \%$ of the IMK values were included in type I and $7 \%$ in type II. The IMK values before and after treatment were statisticaly analysed using the Wilcoxon test. Statisticaly significant results were obtained when comparing the IMK values before and after teatment $(p<0.05)$.

\section{Discussion}

Saliva acts as a buffer agent for various beverages. However beverages like fruit juices or wine are resistent to the acid neutralizing action of saliva and have the capacity to prolong the time of 
REMINERALIZING POTENTIAL OF SALIVA ON PATIENTS HAVING DENTAL EROSIONS DUE TO WINE CONSUMPTION

Table 1. IMK values at baseline and after 5 weeks of treatment using MI Varnish

\begin{tabular}{|c|c|c|c|c|c|c|c|c|c|c|c|c|c|c|c|c|c|}
\hline \multicolumn{18}{|c|}{ IMK values } \\
\hline & & & & & & & & & & & & & & & & Mean & STDEV \\
\hline initial & 0.3 & 0.4 & 0.2 & 0.4 & 0.3 & 0.3 & 0.4 & 0.5 & 0.3 & 0.3 & 0.2 & 0.5 & 0.2 & 0.3 & 0.4 & 0.333 & 0.097 \\
\hline $\begin{array}{l}\text { after } \\
\text { treat. }\end{array}$ & 0.7 & 0.8 & 0.6 & 0.9 & 0.7 & 1 & 0.8 & 0.9 & 0.8 & 0.9 & 0.8 & 1 & 0.8 & 0.9 & 0.9 & 0.833 & 0.111 \\
\hline
\end{tabular}

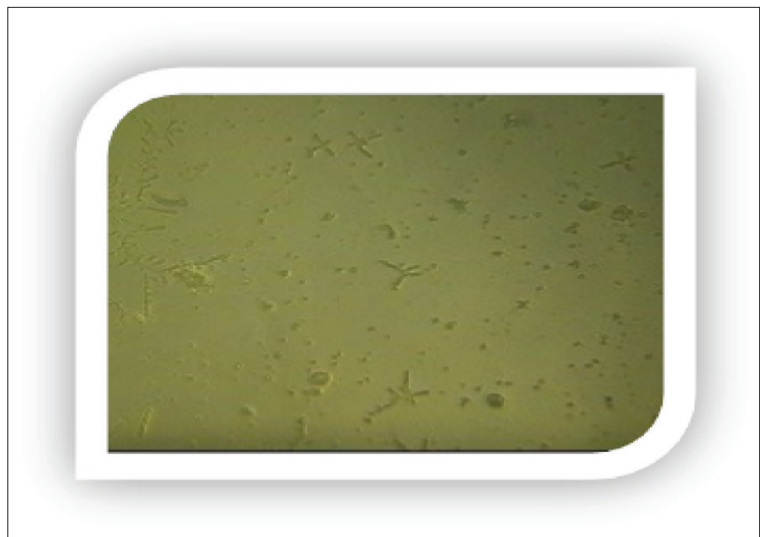

Figure 1. $I M K=0,2$

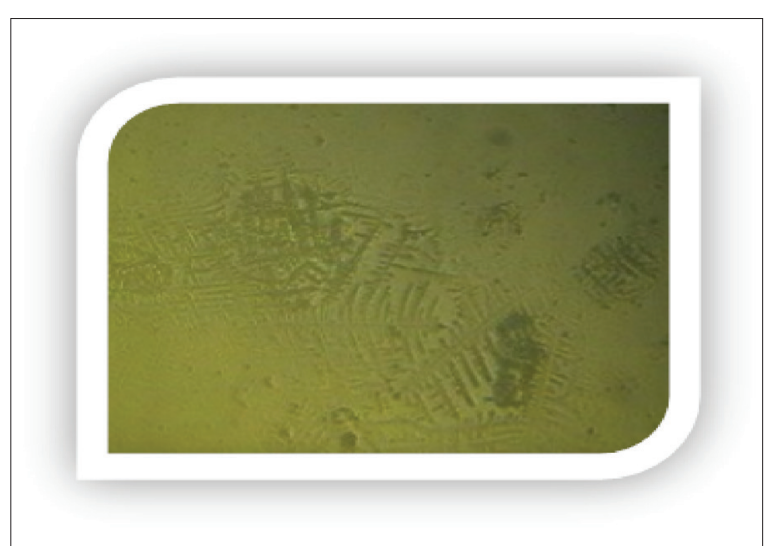

Figure 3. $I M K=0,4$

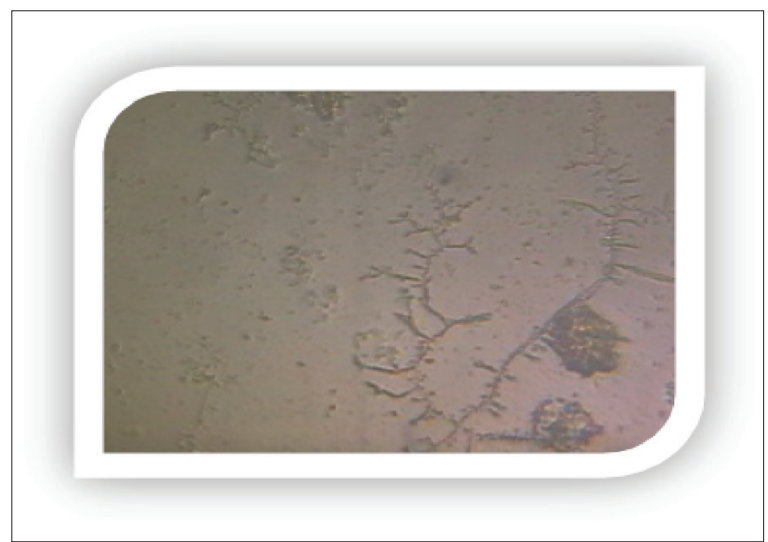

Figure 5. $I M K=0,3$

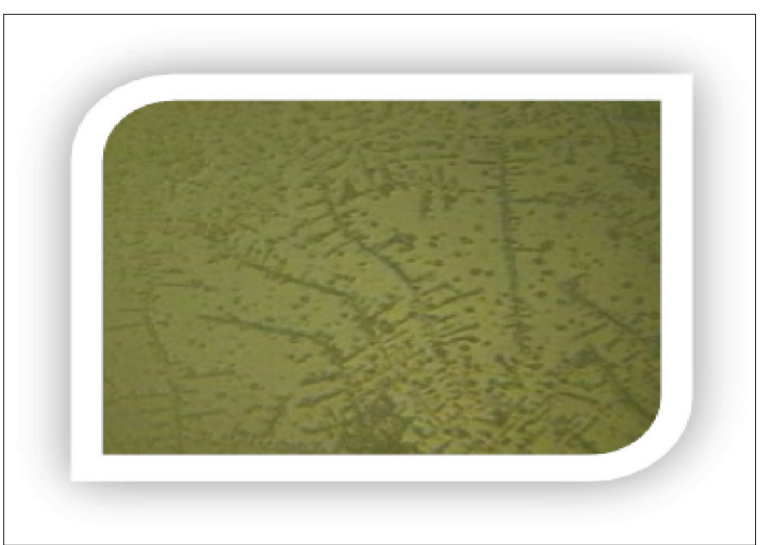

Figure 2. $I M K=0,8$

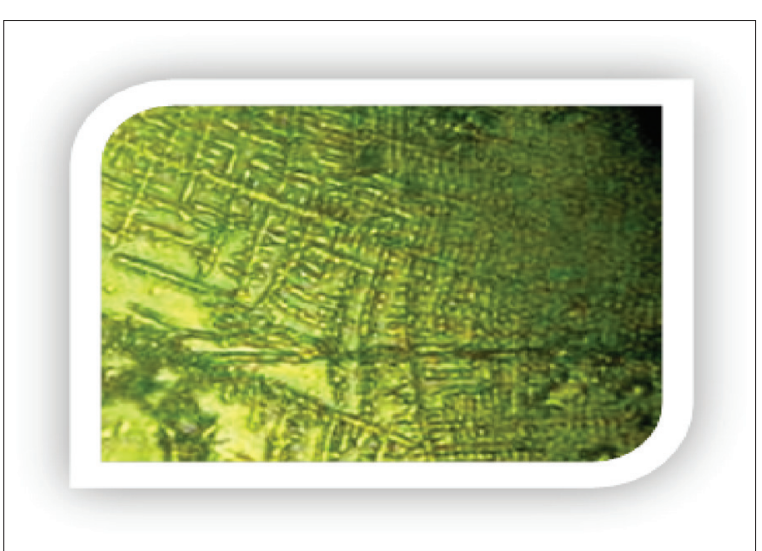

Figure 4. $I M K=0,8$

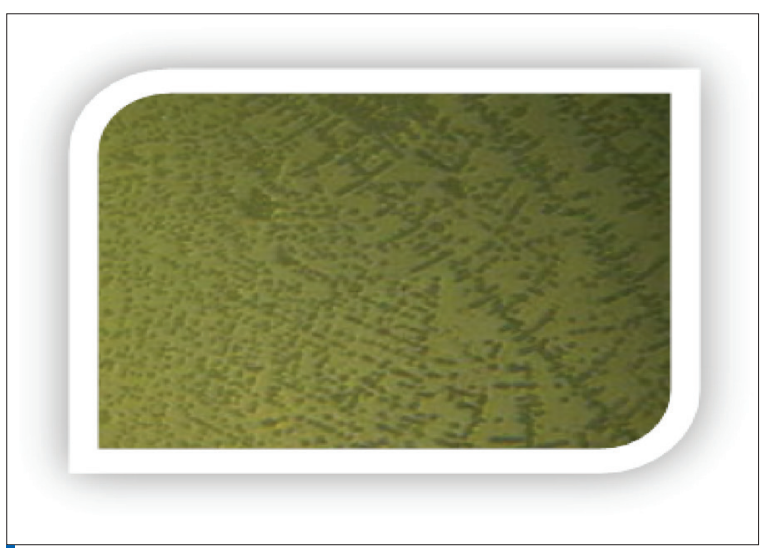

Figure 6. $\mathrm{IMK}=0,8$

Figures 1-6. Examples of saliva micro-crystallization aspects 
$\mathrm{pH}$ dropping. The development, evolution and prognostic of dental erosion depend on the frequency and duration of the acid exposure. The protective biological factors against erosive factors are saliva and acquired pellicle. ${ }^{31-33}$ The remineralizing ability of saliva is influenced both by the minerals levels and the quality and levels of salivary mucins. Mucins are proteins that participate in the saliva bio-crystallization processes and influence directly the increase and development of salivary biocrystals. Salivary mucins also influence the diameter and shape of the anorganic deposits and the type of crystallization in IMK test.

Lennon AM et al. ${ }^{34}$ assessed in vitro the protective ability of a casein-calcium phosphate tooth against dental erosions. The researchers concluded that 12500 ppm AMF gels supply the most effective protection against dental erosion.

The mechanism by which the products containing casein-calcium phosphate reduce erosion is not clearly established yet. Except for the prevention of dental hard tissues demineralization, it was suggested that the product also remineralizes (repairs) eroded enamel and dentine crystals. Ramalingam observed a superficial granular structure formed on the enamel surface. It is highly possible for these structures to represent remineralized enamel crystals. ${ }^{11}$

Our study proved that local treatment with RECALDENT TM (CPP-ACP) MI Varnish ${ }^{\mathrm{TM}}$ influences the remineralizing potential of saliva for patients with dental erosions by increasing the mean IMK value after treatment. The crystallization types also improved significantly. In our study, prior to treatment, most of the patients presented the highest crystals concentration in the middle of saliva droplet. Other studies showed that patients having dental erosions presented separated crystals in the form of a branch or stem, placed relatively evenly over the whole surface of the dried droplet or a large amount of separated stellate crystals of an oval and irregular shape located isometrically. ${ }^{35}$
The major components of the varnish that we tested were casein phosphopeptide, calcium phosphate, amorphous calcium phosphate and fluoride. They can contribute to increase the remineralising potential of saliva and to arrest the erosive effect. Previous studies showed that other products having similar components (Tooth Mousse, GC Corporation, Tokyo, Japan) have good control on tooth erosion, possibly due to anticariogenic remineralizing agent represented by casein phosphopeptide-amorphous calcium phosphate (CPP-ACP) nanocomplex. ${ }^{36}$

The reduction in tooth erosion induced by white wine consumption was clearly demonstrated by Manton (2010) and Piekarz C (2008).9,10

In the absence of a device focused on the early detection of dental erosions, the clinical aspect and the practitioner's experience contribute to the accurate detection in the early stages.6,9-13,34

IMK evaluation is an affordable test to monitor the effectiveness of the non-operative, preventive metods. The methodology is simple, accesible and inexpensive. The principal components of this varnish, casein phosphopeptide (CPPACP) calcium phosphate, amorphous calcium phosphate and fluoride, can contribute to the increase of saliva remineralising potential and to arresting the erosive effect. GC Recaldent Ml Varnish can be recommended to counteract the erosive effect of wine and acid beverages.

\section{Conclusions}

The use of varnishes containing casein phosphopeptide, calcium phosphate, amorphous calcium phosphate and fluoride increases the remineralizing potential of saliva for patients having dental erosions related to frequent wine consumption.

\section{Acknowledgments}

The authors declare no conflict of interest related to this study. There are no conflicts of interest and no financial interests to be disclosed.

\section{REFERENCES}

1. Fauchard P. The Surgeon Dentist or Treatise on the Teeth. Lindsay L. translation from 1746 2nd ed. London, England: Butterworth; 1946;20, 21,40,46,47.

2. Bell T. Abrasion and erosion on the teeth, part 3. Litch WF. ed. The Anatomy, Physiology and Diseases of the Teeth, Philadelphia, PA: Carey \& Lea; 1831.

3. Miller WD. Experiments and observations on the wasting of tooth tissue previously designated as erosion, abrasion, chemical abrasion, denudation, etc. Dental Cosmos 1907; XLIX No. 1:1-23, XLIX No. 2:109-124, XLIX No. 3:225-247.

4. Black GV. A work on operative dentistry. Vol. 1. Pathology of the Hard Tissues of the Teeth. 1st ed. Chicago, IL: MedicoDental Publishing; 1907:39-59.

5. Lussi A, Jaeggi T. Erosion - diagnosis and risk factors. Clin Oral Invest. 2008;12 (1): S5-S13
6. Lussi A, Jaeggi T. Chemical factors. Monogr Oral Sci. 2006; $20: 77-87$

7. Imfeld T. Dental erosion. Definition, classification and links. Eur J Oral Sci. 1996;104(2 (Pt 2)):151-155.

8. Lennon AM, Pfeffer M, Buchalla W, Becker K, Lennon S, Attin T. Effect of a casein/calcium phosphate-containing tooth cream and fluoride on enamel erosion in vitro. Caries Res. 2006;40(2):154-157.

9. Manton DJ, Cai F, Yuan Y, Walker GD, Cochrane NJ, Reynolds C, Brearley-Messer LJ, Reynolds EC. Effect of casein phosphopeptide-amorphous calcium phosphate added to acidic beverages on enamel erosion in vitro. Aust Dent J. 2010;55(3):275-279. 
10. Piekarz C, Ranjitkar S, Hunt D, Mclntyre J. An in vitro assessment of the role of Tooth Mousse in preventing wine erosion. Aust Dent J. 2008;53(1):22-25.

11. Ramalingam L, Messer LB, Reynolds EC. Adding casein phosphopeptide-amorphous calcium phosphate to sports drinks eliminate in vitro erosion. Pediatric Dent. 2005;27(1):61-67.

12. Ranjitkar S, Kaidonis JA, Richards LC, Townsend GC. The effect of CPP-ACP on enamel wear under severe erosive conditions. Arch Oral Biol. 2009;54(6):527-532.

13. Ranjitkar S, Narayana T, Kaidonis JA, Hughes TE, Richards LC, Townsend GC. The effect of casein phosphopeptideamorphous calcium phosphate on erosive dentine wear. Aust Dent J. 2009;54(2):101-107.

14. Wegehaupt FJ, Attin T. The role of fluoride and casein phosphopeptide/amorphous calcium phosphate in the prevention of erosive/abrasive wear in an in vitro model using hydrochloric acid. Caries Res. 2010;44(4):358-363.

15. Vieira AE, Delbem AC, Sassaki KT, Rodrigues E, Cury JA, Cunha RF. Fluoride dose response in $\mathrm{pH}$-cycling models using bovine enamel. Caries Res. 2005;39(6):514-520.

16. Pancu G, Iovan G, Ghiorghe A, Topoliceanu C, Nica I, Tofan N, Stoleriu S, Sandu AV, Andrian S. The assessment of biological parameters and remineralisation potential of saliva in pregnancy. Rev Mat Plastice. 2015;66(12):20512056.

17. Pancu G, Stoleriu S, Iovan G, Gheorghe A, Nica I, Tofan $\mathrm{N}$, Andrian S. On the salivary microscrystallization index variation in patients with dental erosion lesions. IJMD. 2015;5(3):189-193.

18. Martusevich AK, Kamakin NF. Unified algorithm of study of free and initiated biological fluid crystallogenesis. Klin Lab Diagn. 2007;(6):21-24.

19. Martusevich AK, Kamakin NF. Crystallography of biological fluid as a method for evaluating its physicochemical characteristics. Bull Exp Biol Med. 2007;143(3):385-388.

20. Stafne EC, Lovestadt SA. Dissolution of tooth substance by lemon juice, acid beverages and acids from other sources. J Am Dent Assoc. 1947;34(9):586-592.

21. Zero DT. Etiology of dental erosion--extrinsic factors. Eur J Oral Sci. 1996;104 (2 (Pt 2)):162-77.

22. Bartlett DW. The role of erosion in tooth wear: aetiology, prevention and management. Int Dent J. 2005;55(4 suppl
1):277-284.

23. Bartlett D. Intrinsic causes of erosion. Monogr Oral Sci. 2006;20:119-139.

24. Schlueter N, Hardt M, Klimek J, Ganss C. Influence of digestive enzymes trypsin and pepsin in vitro on the progres. sion of erosion in dentine. Arch Oral Biol. 2010;55(4):294299.

25. Giunta JL. Dental erosion resulting from chewable vitamin C tablets. J Am Dent Assoc. 1983;107(2):253-256.

26. Smith BG, Robb ND. Dental erosion in patients with chronic alcoholism. J Dent. 1989;17(5):219-221.

27. Wiegand A, Attin T. Occupational dental erosion from exposure to acids: a review. Occup Med (Lond). 2007;57(3):169-176.

28. Rees J, Hughes J, Innes C. An in vitro assessment of the erosive potential of some white wines. Eur J Prosthodont Restor Dent. 2002;10(1):37-42.

29. Mandel L. Dental erosion due to wine consumption. J Am Dent Assoc. 2005;136(1):71-75.

30. Mok TB, Mclntyre J, Hunt D. Dental erosion: in vitro model of wine assessor's erosion. Aust Dent J. 2001;46(4):263268.

31. Hall AF, Buchanan CA, Millett DT, Creanor SL, Strang R, Foye $\mathrm{RH}$. The effect of saliva on enamel and dentine erosion. J Dent. 1999;27(5):333-339.

32. Hannig M, Balz M. Protective properties of salivary pellicles from two different intraoral sites on enamel erosion. Caries Res. 2001;35(2):142-148.

33. Hannig $M$, Fiebiger $M$, Güntzer $M$, Döbert $A$, Zimehl $R$, Nekrashevych Y. Protective effect of the in situ formed shortterm salivary pellicle. Arch Oral Biol. 2004;49(11):903-910. 34. Lennon AM, Pfeffer M, Buchalla W, Becker K, Lennon $S$, Attin T. Effect of a casein/calcium phosphate-containing tooth cream and fluoride on enamel erosion in vitro. Caries Res. 2006;40(2):154-157.

35. Spinei A, Picos AM, Romanciuc I, Berar A, Mihailescu AM. The study of oral liquid microcrystallization in children with gastro-esophageal reflux disease Clujul Med. 2014;87(4):269-276.

36. Smales RJ, Yip K HK. Prevention and control of tooth erosion. In: Yip K HK, Smales RJ, Kaidonis JA, editors. Tooth erosion: Prevention and treatment. 1st ed. New Delhi: Jaypee Brothers, Medical Publishers (P) Ltd; 2006: 33-46. 


\section{Nicoleta TOFAN \\ DDS, PhD Student \\ Department of Odontology, Periodontology and Fixed Prosthodontics

Dr. Nicoleta Tofan graduated College of Dentary Technique (2002) at Grigore Ghica Voda, Jassy and Faculty of Dental Medicine at "Gr. T. Popa" University of Medicine and Pharmacy, Jassy, Romania (September 2012).

She also participated at Intensive Training Program in Aesthetic Medicine the Injections Module at QClinic Cluj (May 2014) with Professor Adrian Avram and achieved the necessary skills and techniques for performing the Injections with Hyaluronic Acid.

Also she attended at the Worksop "Global Approach in Facial Rejuvenation by Injecting Hyaluronic Acid" organised by the Romanian Society of Dermatology in May 2016.

Dr. Nicoleta Tofan has published 2 articles in Chemistry Magazine (December 2015) and in Romanian Journal of Oral Rehabilitation.

\section{Questions}

\section{Researches of Leus showed that the patients with low remineralizing capacity of saliva presented in microscopy}

a. A "fern" aspect of saliva crystals;

b. A few crystals in visual field or needle-shaped crystals;

c. The highest crystals concentration in the middle of saliva drop;

d. A "corncob" aspect of saliva crystals.

\section{The erosive potential of red wine, white wine, and champagne is related to the pres- ence of:}

$\square$ a. Lactic acid, phosphoric acid, tartaric acid;

b. Citric acid, phosphoric acid, malic acid;

c. Lactic acid, citric acid, malic acid, tartaric acid;

$\square$ d. Stearic acid, linoleic acid, malic acid.

The use of MI Varnish containing casein phosphopeptide, calcium phosphate, amorphous calcium phosphate and fluoride:

$\square$ a. Increased only the mean IMK values;

$\square$ b. Had no effect on IMK values;

$\square$ c. Decreased the type of saliva crystallization;

$\square$ d. Increased the mean IMK values and type of saliva crystallization.

\section{The types of saliva micro-crystallization were represented by:}

$\square$ a. Needle-shaped crystals;

$\square$ b. Tree-shaped crystals;

c. Cubic-shaped crystals;

$\square \mathrm{d}$. All the previous answers are correct. 